\title{
High Resolution Supply Chain Management - A Structural Model for Optimized Planning Processes Based on Real-Time Data
}

\author{
Volker Stich, Tobias Brosze, Fabian Bauhoff, Florian Gläsner, \\ Simone Runge, and Marcel Groten \\ Institute for Industrial Management at RWTH Aachen University, \\ Pontdriesch 14/16, 52062 Aachen, Germany \\ \{Volker.Stich, Tobias.Brosze, \\ Fabian.Bauhoff, Florian.Glaesner, Simone.Runge, \\ Marcel.Groten\} afir.rwth-aachen.de
}

\begin{abstract}
The following paper presents an approach for enabling manufacturing companies to cope with dynamic environment conditions and the increasing planning complexity of present supply chains. High Resolution Supply Chain Management (HRSCM) strives to meet these challenges by applying cybernetic principles to the Production Planning and Control (PPC). Therefore, standardized information channels and coordination mechanisms are defined to be able to react even faster and more flexible. The presented structure of the HRSCM is derived from principles of the Viable System Model. Based on this the different system elements of the HRSCM, their functions and their interactions are described. Finally it is outlined how the developed model will be experimentally evaluated and gradually enhanced in future to enable improved decisions on all levels of production under volatile environmental conditions.
\end{abstract}

Keywords: production management system, high resolution supply chain management, system engineering, cybernetic, adaptability.

\section{Introduction}

Today, the production industry is increasingly confronted with the influences of a dynamic environment and the ensuing continuously increasing planning complexity [1], [2]. Therefore, a successful Supply Chain Management depends beside the process efficiency on high information availability for being able to handle this challenge. In contrast, the lack of standardized interfaces and channels of information combined with complex processes and a low automation level characterizes the current status in many companies. The consequences are wrong decisions in the planning processes, caused by poor communication, data based on experience and the application of average values, as well as uncertain values of demand, costs and inventory. Current solution approaches try to tackle these problems by using highly sophisticated and centralized planning methods [3]. These centralized planning approaches constrain the ability of companies to react quickly and flexibly on internal 
and external disturbances. This leads to an increasing gap between plans and reality and a decreasing effectiveness of companies [4].

High Resolution Supply Chain Management aims to reduce the planning complexity by applying decentralized, self-optimizing control loops to the Production Planning and Control (PPC). Changable organizational structures and processes, a high information transparency, increased capacity flexibility, as well as the continuously synchronization of the concerned planning elements are necessary preconditions for ensuring the achievement of the above mentioned aims [1], [2].

\section{Methodological Approach and Preconditions for HRSCM}

Conditioned by technological innovations like RFID and the informational integration of companies, operational information are recently available in a new level of granularity and time offset [5]. The HRSCM approach uses such information in the context of production management and combines the functional principle of control loop based planning with an appropriate organizational structure for production management.

In this context the term "High Resolution" stands for the new quality of information referring to granularity and time offset. To fulfill the challenge of a higher changeability, it is necessary to remove the static planning processes of centralcontrolled approaches [4], [6]. The object in focus is specified by the term "Supply Chain Management" (SCM). HRSCM offers a framework for allocating all intra- and inter-company SCM activities within the focus of a company's order processing.

Conditioned by the interdisciplinary character of HRSCM, the approach has to meet technological and organizational requirements. The technological preconditions for the HRSCM are given by the necessity for realistic and achievable values for planning, which depend on the generation of information in the required quality by e.g. sensors and their availability through IT systems. The organizational preconditions are determined by the complexity of organizational entities and their dynamic environment. The organizational structure of HRSCM must be able to handle this complexity with due regard to maintain the internal stability and the fit to the external environment.

\section{Findings: Structure of HRSCM}

The structure of the HRSCM reference model is determined by the above-mentioned preconditions. The ability for handling the company complexity and the influences of a dynamic environment of production industry, as well as the reduction of efforts for coordination, can only be achieved by using structural decentralization and high reactivity [7].

Different models have been tested for their eligibility for fulfilling the mentioned requirements: Architecture of Integrated Information Systems (ARIS), Dortmund Process Chain Model and the Stuttgart Business Model. These models describe companies in a steady-state status and disregard the issues of changeability, decentralization, self-optimizing and the adaption to a dynamic environment. 
An established management cybernetic reference model, which meets the requirements, is the Viable System Model (VSM) [8], [9], [10]. Therefore it is appropriate to use the VSM as a structural framework for HRSCM.

\subsection{Viable System Model}

The VSM was evolved by BEER in the 1960s as a management model to support managers dealing with complex management processes. BEER underlines, that viability in the context of business management does not mean the bare survival of a firm. Rather it is to be understood as a continuous maintenance of the system identity within a steadily changing environment [11].

Three fundamental cybernetic principles are the basis of the VSM. Viability implies that a company must react to internal and external disturbances in an appropriate way, in order to sustain its existence. Recursiveness is a principle to structure organizational systems in a self-similar way. Hence, a viable system is a composition of nested systems, which are viable systems, too [6], [12]. In this context, autonomy means that a system can act independently as long as it is in accordance with its meta-systems' rules [11], [13].

BEER introduces for realizing these three principles a specific structure for systems, which is a necessary condition for their viability. According to that every viable system consists of five subsystems, which have to fulfill specific functions (see Figure 1).

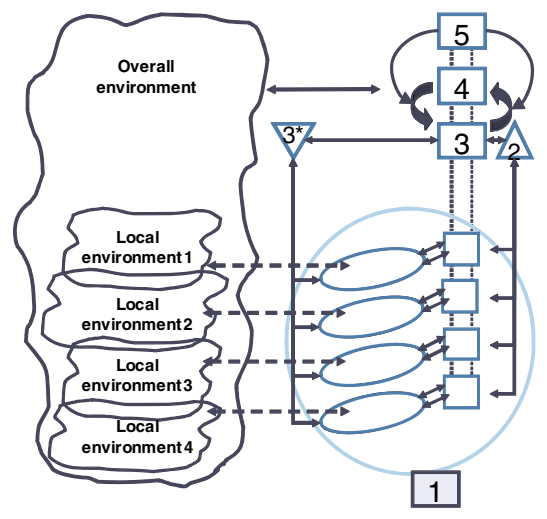

Fig. 1. Structure of the VSM, following [11], [12], [13], [14]

System 1 contains the operative units, which are responsible for the fulfillment of the essential purpose of the organization. The elements of System 1 come with relative autonomy, which means that they plan, execute and control the assigned task with consideration of their given target system and boundaries. They are embedded in a multi-level managerial structure (Systems 2-5). The coordination system (System 2) ensures that the operative units cooperate for a common purpose. The target systems and boundaries of autonomy of the operative units are defined by the operative management (System 3). System 3 obtains information on the internal stability from the managerial units of System 1, the coordination system and the monitoring system 
(System $3 *$ ). From above it gets information and instructions from the hierarchically superior Systems 4 and 5. The assignments of System 4 and 5 include the observation and analysis of the relevant environment (System 4), as well as the definition of the system identity and the overall target system [15].

\subsection{Application of Viable System Model to Supply Chain Management}

The VSM-based reference model of SCM is characterized by an explicit process orientation and includes the whole order processing from the processing of an offer, to the production and delivery of the finished product [16]. In contrast to a conventional order processing, the cybernetic approach increases the ability of dealing with internal or external disturbances and ensures a continuous checking for necessary system adaptions. As already mentioned in chapter 2 the focus is on the inter-factory order processing. Consequently the selected operational units are the processes of the order processing: quotation processing, projecting, construction, ordering, purchasing, manufacturing, assembling, shipping and after sales.

These processes of order processing are embedded in meta-systemic managerial structure, consisting of the operative Process Management and Control, the Process Coordination Center and the Tactical, Strategic and Normative Production Management (see Figure 2). The aim is to provide the operative units with the greatest possible autonomy, which is only limited by the necessity for coherency of the overall system. The extent of autonomy depends on the situational environmental disturbances, thus it is variable over the time. In general case all tasks of order processing are handled decentralized by the operational units. The meta-systemic management units are only in charge for sustaining the synchronization of the overall system [15]. For handling these disturbances and dynamic environment conditions it is necessary to specify dynamic reference value corridors, reference values with high granularity and accuracy, as well as to take care for short response-times for every system level.

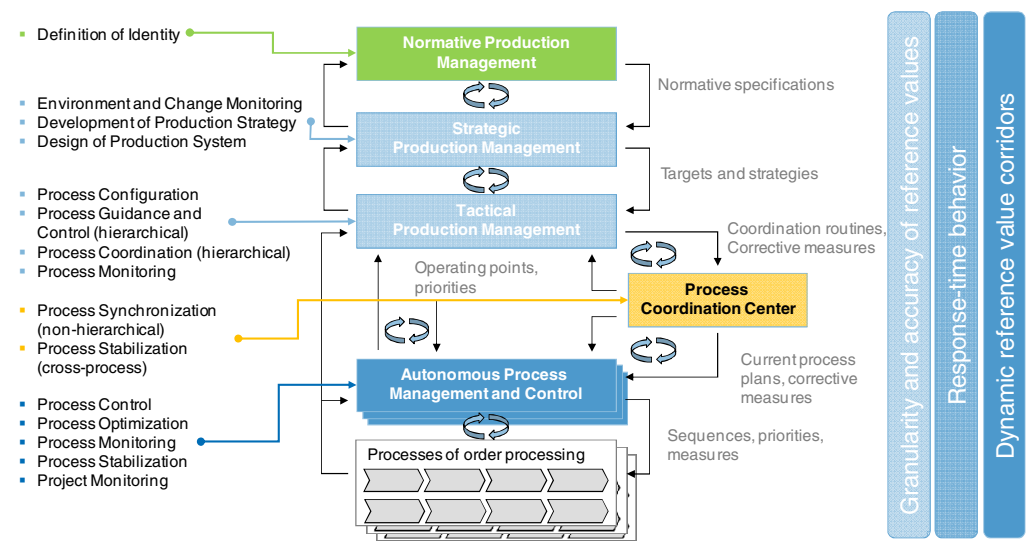

Fig. 2. Assignment of the order processing to the structure of the VSM 
The functions and interactions of the elements of a changeable Production Management System are briefly specified below [15].

The Autonomous Process Management and Control consists of the local management and control units of the above mentioned operational processes. The tasks of the local Process Management units consist in the controlling and monitoring of the operative processes. It is responsible for determining the local target systems of the processes in coordination with the Tactical Production Management. The instruction of the higher managerial levels are interpreted and passed as concrete measures to the different processes. Furthermore the Process Management units are competent to define rules of conduct, routines, sequences and priorities for the processes, as well as developing and optimizing methods and tools to eliminate local disturbances. The local process control units gather and observe defined process indices and share status messages of orders and resources with the control units of the other processes. Beside this they are in charge for the planning and execution of routines to react on known disturbances, as well as implementing measures of the managerial units.

The stabilization, synchronization and the project controlling of the operative processes is ensured by the Process Coordination Center. In the context of stabilization of the processes it is responsible for controlling the observance of the operating points, the damping of oscillations between the processes by using standardized measures and the implementing of formal and informal communication channels. Additionally tasks are the controlling of defined priority rules and the usage of routines for synchronizing the different measures of and between the processes. Tasks of project controlling consist in the monitoring of the order progress and basic dates and the implementing of measures to ensure the order fulfillment, if there is a deviation compared with the plan.

The overall internal stabilization of the operative processes is the guiding principle of the Tactical Production Management. It defines guidelines and scopes of action for the Process Management and Control and the Process Coordination Center. The four primary duties are the process configuration, the process controlling of the internal operative processes at a higher level, the superior process coordination and the monitoring of the operative processes. For accomplishing these duties, it is exemplarily competent to define operating points for the overall system, to specify superior targets, priorities and rules of conduct, to arrange adaptations of the system structure and to optimize the used measures and tools for ensuring the striving for the common target system.

The long-term maintenance and improvement of the companies' competitive advantages by anticipating possible future prospects, adapting the organizational structure to dynamic environmental changes and the consequent alignment of the production system are the key aspects of activity of the Strategic Production Management. Consequent subtasks encompass the monitoring of the environment, the strategic production development and configuration of the production system. The continuous matching between the market-driven requirements and the internal capability to fulfill these is a prerequisite for deriving strategic factors of success and defining priorities and challenges for the production logistics. Within the framework of the production configuration for example logistical targets and defaults of location planning are defined. 
The highest level of the production management system is represented by the Normative Production Management. It accounts for aligning the overall target system with due regard to the companies' identity, values and norms. That leads to the desired condition of the overall production system.

Concluding it is important to straighten out that the introduced reference model is not constructed in a classically hierarchical way. The authority results from the different logical capacity of the management units.

\section{Application and Enhancement of the Reference Model}

In the following a description of how the developed model will be applied and enhanced in future is given. First, the general approach of concretion based on experiments is described and afterwards it is outlined what has to be considered when performing experiments.

Based on the developed cybernetic reference model, test-beds of a self-optimizing production will be build and studied in different use cases and the results will be evaluated. Different disciplinaries will be incorporated and the influence of human decision making is an important factor to examine. In this way a holistic view on a socio-technical production system under consideration of the factors human, technology and organization will be reached.

To assure analysis on all levels of production systems, three use cases have been defined. These use cases will address the comprehensive application of selfoptimizing control. The control loops on cell-level, Production Planning and Control (PPC) as well as on Supply Chain level will be integrated.

One use case addresses the supply chain level. The use of high-resolution data in the supply chain level for local planning will be investigated. Questions regarding the granularity of information are considered as well as the visualization of information for the planner. Another use case will focus on the interface between human and machine as well as the design and coordination of autonomous sub-systems on production level to converge a global optimum under consideration of all of these aspects. The third use case will lay its focus on the integration of human decision making in complex situations in the context of production control.

The test-beds of these use cases will be linked gradually and will be integrated afterwards in a real-production environment. Results will be reflected against the developed model to identify weaknesses and improve the model based on scientific results. The model integrates control loops on different levels and thus enables improved decisions on all levels of production under volatile environmental conditions. This leads to adaption of an optimal operating point and integrates the deterministic and the cybernetic perspective.

As the test-beds will be linked and integrated in a real production environment, the resulting potential of integrated research means a paradigm shift in research of production systems. Such research environments establish new ways of analyzing the connections in production systems.

Test-beds enable experimental research in real production environments. When performing experiments in real-life the complexity of the experiments increases significantly [17]. Thus, the considered system shows a high complexity. In order to 
control the systems complexity it is necessary to manage the experimental real production environment in a pre-defined manner. In this way it is possible to obtain out of the high amount of factors in a complex system a well-structured analysis that delivers the required results.

For that reason, a statistical design of experiments is a possible approach to decrease the complexity while maintaining high information content of the experimental results [18].

When applying the method of statistical design of experiments, in first place an experimental design has to be developed. One has to take into account the information that is required to choose the correct factors. For that reason, it is necessary to identify all possible factors in a screening of the experimental environment. This enables to differentiate significant factors from non-significant factors. Due to this reduction of factors, first experiments can be done with an acceptable amount of time and money.

It is recommended to choose a high distance between the factors in a first set of experiments, so that it is possible to identify first influences of the chosen factors on the system behavior [17]. Where significant factors on the system behavior can be identified, these can be studied in further experiments with an increasing amount of factors. In this way a good ratio between input resources and significant results can be achieved.

In the following figure 3 the context between the factors (Input), the system and the results is shown. There are factors which can be modified by the design of experiments and those who are given by the experimental environment. Depending on the behavior of the system results can be obtained for certain factors [17], [18].

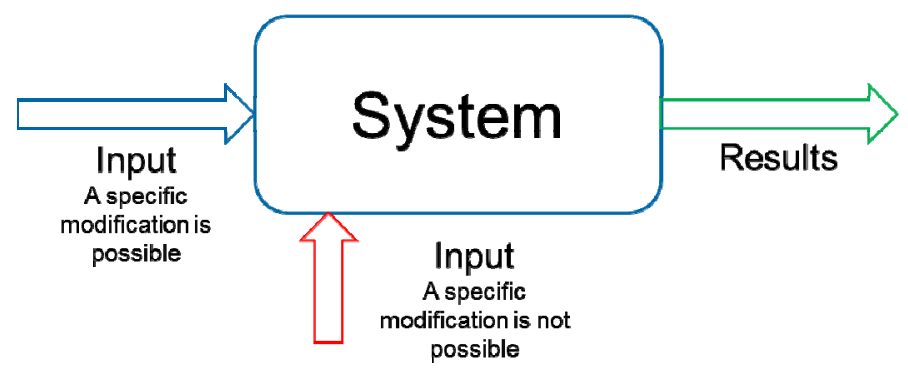

Fig. 3. Schematic representation of a System with different types of input and system-dependent results

By the application of statistical design of experiments, it is also possible to identify not only the main effects, but also interactions between factors. Using a computer, statistical analysis can be obtained with low effort and in this way the significance of certain factors can be proved easily. 


\section{Conclusion}

Within the paper a changeable Production Management System has been presented, for decreasing the planning complexity in Supply Chains and improving the handling of dynamic environment conditions within PPC. After introducing the preconditions of the model, we have derived the structural framework of the HRSCM from the Viable System Model and specified the functions of the system elements and their interactions. Further research is needed to verify and validate the model. To that purpose use-cases on different levels of production have been defined and the results of these experiments will we contribute to further enhancement of the model. Thereby a specific focus should be dedicated to the determination of the granularity and accuracy of the individual reference values, the specific response-time behavior and the corresponding dynamic reference value corridor. As shown before an adequate way for the investigation could be the statistical design of experiments as this method allows generating statistically proofed results in an acceptable amount of time.

\section{References}

[1] Brosze, T., Bauhoff, F., Stich, V., Fuchs, S.: High Resolution Supply Chain Management - Resolution of the Polylemma of Production by Information Transparency and Organizational Integration. In: Vallespir, B., Alix, T. (eds.) APMS 2009. IFIP AICT, vol. 338, pp. 325-332. Springer, Heidelberg (2010)

[2] Schuh, G., Stich, V., Brosze, T., Fuchs, S., Pulz, C., Quick, J., Schürmeyer, M., Bauhoff, F.: High resolution supply chain management: optimized processes based on selfoptimizing control loops and real time data. In: Production Engineering, pp. 433-442. Springer, Heidelberg (2011)

[3] Meyer, J., Wienholdt, H.: Wirtschaftliche Produktion in Hochlohnländern durch High Resolution Supply Chain Management. In: Supply Chain Management III, vol. 7, pp. 2327 (2007)

[4] Fleisch, E., Fuchs, S., Gottschalk, S., Güthenke, G., Höhne, T., Jacobs, G., Junker, F., Millarg, K., Narr, C., Nyhuis, P., Schuh, G.: High Resolution Production Management. Auftragsplanung und Steuerung in der individualisierten Produktion. In: Brecher, C., Klocke, F., Schmitt, R., Schuh, G. (eds.) Wettbewerbsfaktor Produktionstechnik. Aachener Perspektiven, pp. 451-472. Shaker, Aachen (2008)

[5] Fleisch, E., Müller-Stewens, G.: High Resolution Management: Konsequenzen der 3. ITRevolution auf die Unternehmensführung. Schäffer-Poeschel, Stuttgart (2008)

[6] Beer, S.: Brain of the firm: the managerial cybernetics of organization. The Penguin Press, London (1972)

[7] Frank, U., Giese, H., Klein, F., Oberschelp, O., Schmidt, A., Schulz, B., Vöcking, H., Witting, K.: Selbstoptimierende Systeme des Maschinenbaus. Definitionen und Konzepte. Bonifatius GmbH, Paderborn (2004)

[8] Rüegg-Stürm, J.: Das neue St. Galler Management-Modell. Grundkategorien einer integrierten Managementlehre: Der HSG-Ansatz. Haupt, Bern (2003)

[9] Schwaninger, M.: Intelligent organizations. Powerful models for systemic management. Springer, Berlin (2009)

[10] Westkämper, E., Zahn, E.: Wandlungsfähige Produktionsunternehmen. Das Stuttgarter Unternehmensmodell. Springer, Berlin (2009) 
[11] Beer, S.: The heart of enterprise. Wiley, Chichester (1979)

[12] Malik, F.: Strategie des Managements komplexer Systeme. Ein Beitrag zur ManagementKybernetik evolutionärer Systeme. Haupt, Bern (2006)

[13] Gomez, P.: Die kybernetische Gestaltung des Operations Managements. Eine Systemmethodik zur Entwicklung anpassungsfähiger Organisationsstrukturen. Haupt, Bern (1978)

[14] Espejo, R., Harnden, R.: The viable system model. Interpretations and applications of Stafford Beer's VSM. Wiley, Chichester (1989)

[15] Brosze, T.: Kybernetisches Management wandlungsfähiger Produktionssysteme. Dissertation RWTH Aachen, Aachen (2011)

[16] Balve, P., Wiendahl, H., Westkämper, E.: Order management in transformable business structures - basics and concepts. In: Robotics and Computer Integrated Manufacturing, vol. 17, pp. 461-468 (2001)

[17] Siebertz, K., van Bebber, D., Hochkirchen, T.: Statistische Versuchsplanung - Design of Experiments. Springer, Heidelberg (2010)

[18] Kleppmann, W.: Taschenbuch Versuchsplanung - Produkte und Prozesse optimieren. Carl Hanser Verlag, München (2008) 